\title{
MICROPHTHALMIA, PROLACTIN AND FERTILITY IN RATS
}

\author{
L. G. BROWMAN
}

Department of Zoolog, University of Montana, Missoula, Montana 59801, U.S.A.

(Received 31st December 1969, revised 27th Fuly 1970)

Summary. Female rats from the strain with severe bilateral microphthalmia have histories of very low fertility. The fact that the rats of this strain have a number of sub-optimal reproductive characteristics, which are distinct from their lactation performance, is not believed to be of primary significance in their poor reproductive capacity.

Lack of adequate milk production by recently delivered microphthalmic females is the most common defect resulting in the death of young born alive. Over a period of 3 years, the strain had a record of only $30 \%$ of litters raised to weaning age.

Supplements of daily injections of LtH commencing on Day 18 of pregnancy, and continuing for the first 10 days of nursing caused a spectacular increase in the number of litters raised to weaning.

\section{INTRODUGTION}

Rat strains with severe microphthalmia can only be maintained with difficulty. Yudkin (1927) was unable to maintain such a strain, and King (1931) was only able to do so for 6 years. She reported that the rats did not show the "vitality and fertility equal to that in the extracted race from which they came" and that "females were unable to rear their young." Hain (1936) maintained a microphthalmic strain of rats for fourteen generations.

Browman (1967) reported that although a microphthalmic strain could be maintained, the reproductive performance was very poor. A large number of females had to be bred in order to keep the colony going. Eaton (1937) reported an increased percentage of sterility in guinea-pigs with microphthalmia as inbreeding progressed. Chase (1941), on the other hand, reported that anophthalmia had no effect on the reproductive performance in mice.

Many female rats with microphthalmia produce live litters but few of the young survive to weaning. The ovulation and implantation mechanisms are not felt to be the critical factors involved, even though the average litter size, at birth, of microphthalmic females is 15 to $20 \%$ lower than that produced by normal females.

The primary cause of such impaired reproductive ability was the poor capacity for lactation on the part of the recently parturient female. Of 260 females from the microphthalmic strain delivering young during a 3-year period, only seventy-eight females $(30 \%)$ raised the young to the weaning age of 28 days. 
It seemed worthwhile to explore the several facets of the reproductive cycle of these females and then subject them to appropriate hormone treatment to see if lactation could be improved.

\section{METHODS}

All the experimental and control rats were maintained simultaneously under the same standard light, ventilation, watering and unrestricted feeding regimens in the same animal room. The number of animals in each cage, the size and kind of cage, the bedding and frequency of handling were kept the same in every category by the same animal caretakers and investigator.

The time of opening of the vaginal introitus was recorded for all females. From this time, vaginal smears were taken daily until the animals were killed after at least three periods of pregnancy or at about 10 months of age. A female was allowed no 'rest period' after delivery, the death of her young, or weaning, but was re-introduced promptly into the breeding cage. All pregnant or lactating females were checked twice daily.

The hormones employed were diluted with sterile Ringer's mammalian saline and injected subcutaneously (s.c.) to a total volume of $0.5 \mathrm{ml}$ daily. Prolactin, NIH P-B-2-Bovine was used with the early series. The luteotrophic hormone ( $\mathrm{LtH}$ ) Sheep Gland, Nutritional Biochemical Corporation, was used in all other series. The ACTH (Corticotrophin), injectable Bovine NBC, was also diluted with Ringer's mammalian saline and injected s.c. in given doses.

Artificially blinded (bilateral enucleation) females derived from the normal colony had their eyes removed while under hypothermia with a fine curved scissors on the day of birth. Thereafter, they were treated exactly like the normal and microphthalmic females.

\section{RESULTS}

\section{Vaginal opening}

Vaginal opening in young female rats with severe microphthalmia or artificially blinded rats tended to occur at a later age than in the females from the normal colony (Table 1).

TABLE 1

AVERAGE AGE AT VAGINAL OPENING OF RATS FROM NORMAL, MICROPHTHALMIC AND ARTIFICIALLY BLINDED COLONIES

\begin{tabular}{l|c|c}
\hline \multicolumn{1}{c|}{ Category } & $\begin{array}{c}\text { No. of } \\
\text { animals }\end{array}$ & $\begin{array}{c}\text { Average age } \\
(\text { days } \pm S . E .)\end{array}$ \\
\hline Normal colony & 12 & $43 \cdot 6 \pm 0.71$ \\
Young from above colony & 64 & $44 \cdot 6 \pm 0.86$ \\
Microphthalmic colony & 14 & $56 \cdot 6 \pm 3 \cdot 11$ \\
Young from above & & $47.2 \pm 1.19$ \\
microphthalmic colony & 45 & $47 \cdot 2 \pm 1.65$ \\
\hline Artificially blinded colony & 10 & $52 \cdot 7 \pm 1 \cdot 6$ \\
\hline
\end{tabular}




\section{Oestrous cycles}

The usual oestrous cycles of the microphthalmic females were significantly longer $(P<0.01)$ than those of the normal colony: normal, $4.2 \pm 0.06$ days; microphthalmic, $4 \cdot 6 \pm 0 \cdot 13$ days; artificially blinded, $4 \cdot 3 \pm 0 \cdot 16$ days.

\section{Receptivity}

The routine breeding procedure was to place up to a maximum of seven females in the breeding cage (18 in. $\times 24$ in. $\times 15$ in. high) with two males. Gontrol and experimental animals were observed simultaneously to reduce differences in reproductive performance due to seasonal factors.

The microphthalmic females did not accept the male as soon as the normal females. Table 2 indicates the average number of days that elapsed from the day the females were placed in the breeding cage until spermatozoa were found in the vaginal smear. This period was greater for microphthalmic females than for the females from the normal colony. The data includes observations covering the three first matings.

\section{TABLE 2}

SEXUAL REGEPTIVITY OF FEMALE RATS FROM NORMAL, MICROPHTHALMIC AND ARTIFICIALLY BLINDED GOLONIES

\begin{tabular}{l|c|c}
\hline \multicolumn{1}{c|}{ Category } & $\begin{array}{c}\text { Ave. no. of days } \\
\text { to first sperm. in } \\
\text { vaginal smear } \pm \text { S.E. }\end{array}$ & $\begin{array}{c}\text { Ave. no. of days from } \\
\text { exposure to males until } \\
\text { females littered } \pm \text { S.E. }\end{array}$ \\
\hline Normal colony females & $5 \cdot 8 \pm 0.86$ & $28 \cdot 4 \pm 0.82$ \\
Microphthalmic females & $8 \cdot 8 \pm 1.06$ & $32 \cdot 8 \pm 1.38$ \\
Artificially blinded females & $6 \cdot 1 \pm 0.94$ & $36.7 \pm 3.37$ \\
\hline
\end{tabular}

Female rats often avoided the male or, when two males were present, they occasionally interfered with each other in attempting to mount a female in heat. This occurred more frequently when both males had severe bilateral microphthalmia. The artificially blinded females were mated to normal-eyed males.

While in the breeding cage, the females from the normal colony had a total of only four individual oestrous periods (vaginal cornification) in which no spermatozoa were found in the vaginal smear and no pseudopregnancy occurred. The females continued on into the next normal cycle. The artificially blinded females, as a group, experienced three such oestrous periods but in the case of the microphthalmic females, twenty-five such periods of vaginal cornification occurred in which no spermatozoa were found in the vaginal smear during the same period of time.

The presence of spermatozoa in the vaginal smear cannot be taken as a guarantee that the female will become pregnant. A number of such females became neither pseudopregnant nor pregnant but continued on to the next oestrous cycle. Two artificially blinded females had two such cycles and the microphthalmic females had eleven such cycles. With only two exceptions, the normal females in this series of observations always became pregnant if spermatozoa were present. 
The following two examples illustrate the point. Microphthalmic female (No. 567) had spermatozoa in the vaginal smears of 27 th June and 1st July, and littered on 24th July. Microphthalmic female (No. 568) had spermatozoa in the smears of 7 th and 13th July and littered on 5th August.

\section{Pseudopregnancy}

Pseudopregnancy occurred infrequently in the normal colony. Only two of the twelve females exhibited pseudopregnancy (one period each) during their life time of approximately 10 months (Table 3 ).

One of the artificially blinded females proved sterile. Whenever spermatozoa were found in the vaginal smears, this female invariably became pseudopregnant and never produced a litter. Of the two microphthalmic females which exhibited pseudopregnancy, one (No. 557) never gave birth to a litter, while the other (No. 558) gave birth to two litters.

TABLE 3

OCCURRENCE OF PSEUDOPREGNANCY IN RATS FROM NORMAL, MIGROPHTHALMIC AND ARTIFIGIALLY BLINDED GOLONIES

\begin{tabular}{l|c|c|c|c|c}
\hline \multicolumn{1}{c|}{ Category } & $\begin{array}{c}\text { No. of } \\
\text { animals }\end{array}$ & $\begin{array}{c}\text { Ave. age at } \\
\text { autopsy (days) }\end{array}$ & $\begin{array}{c}\text { No. of females } \\
\text { exhibiting } \\
\text { pseudopregnancy }\end{array}$ & $\begin{array}{c}\text { Total no. of } \\
\text { pseudopregnant } \\
\text { rats }\end{array}$ & $\begin{array}{c}\text { Ave. length of } \\
\text { pseudopregnancy } \\
\text { (days) }\end{array}$ \\
\hline Normal & 12 & 310 & 2 & 2 & $13 \cdot 5$ \\
Artificially blinded & 10 & 306 & 4 & 17 & $13 \cdot 9$ \\
Microphthalmic & 14 & 311 & 2 & 15 & $12 \cdot 3$ \\
\hline
\end{tabular}

\section{Length of gestation}

There was a significant difference $(P<0.001)$ between the normal and microphthalmic animals in the lengths of their respective gestation periods. Those of the normal females averaged $21.6 \pm 0.08$ days compared with $22.5 \pm$ $0 \cdot 12$ days for the microphthalmic females. The difference between the normal and the artificially blinded females, $21 \cdot 6 \pm 0.08$ compared with $22 \cdot 1 \pm 0 \cdot 17$, was significant $(P<0.02)$ and there was a borderline significance $(P>0.05)$ between the artificially blinded and microphthalmic females, $22.1 \pm 0.17$ compared with $22.5 \pm 0 \cdot 12$. In general, the normal females delivered their young on the 22nd day, and the microphthalmic females on the 23rd day of pregnancy.

\section{Survival time of live-born young}

A number of females which had given birth to live young were routinely observed in order to determine the maximum survival time of the young which never reached the age to be weaned. Parturient female rats tend to eat their stillborn young.

In the observation group, there were only three normal females which severely mutilated or partially consumed some of their live young on Day 1 . In the five litters observed from these three females, the average survival time of their young born alive, some of which were 'maternal casualties' was 1.4 days (range 1 to 3 days). No young died of starvation. 
In the thirteen deliveries observed in the artificially blinded group, cannibalism was not the significant factor in the death of young born alive. Inadequate lactation on the part of the female resulted in the death of the young as revealed by their emaciated condition, and the absence of milk in their stomachs. The survival time in these young was an average of 3.9 days, with a range of 1 to 10 days.

Females with microphthalmia also tend to eat their stillborn young, so that the numbers born dead were not always observed. In a sample of nine litters born to microphthalmic females, where whole carcasses of dead young were still available for autopsy after Day 1 , the usual condition was one of emaciation, no milk was found in the stomach, and the body weights averaged less than the average birth weights. The average survival time in these nine litters was 3.5 days (range 1 to 7 days). The emaciated young were frequently observed to be so weak by the 3rd and 4th day, that they appeared to be unable to utter any sound.

Whereas some of the young born to normal females were mutilated or partially eaten, the majority of live young born to microphthalmic females died from lack of milk. Microphthalmic females generally exhibited maternal care. They crouched over the young, corralled them into a compact group, and encouraged nursing. Although the young attempted to suck, they apparently received inadequate nourishment, and gradually weakened and died. Only in two instances did the female ignore the young and allow them to scatter about in the nesting material.

\section{The occurrence of oestrus while nursing}

Young were removed routinely from the nursing female rat on Day 28. In some of the females, oestrous cycles reappeared before the removal of their young, even though the young were still attentive at the nipples. Oestrus was detected on Day $21.0 \pm 0.08$, counting from the date of delivery, in twenty out of twenty-nine $(70 \%)$ nursing normal females; on Day $23.5 \pm 1.2$, in six of fifteen artificially blinded females $(40 \%)$; and on Day $21 \cdot 1 \pm 1 \cdot 3$, in seven of fourteen microphthalmic females $(50 \%)$. The other females resumed cycles after the young were removed on Day 28.

\section{Reproductive success}

The data in Table 4 indicate that although the reproductive success of the microphthalmic females was poor, it was better than the 3-year average for the microphthalmic-female colony mentioned earlier. When a microphthalmic female did lactate, the young were nursed to the weaning age essentially as well as by the normal females.

\section{Prolactin}

A series of microphthalmic females were subjected to a regimen of hormone treatments to determine the effectiveness of the hormones in restoring normal lactation (Table 4) and nursing success.

Prolactin ( $\mathrm{LtH})$ appeared to improve lactation in the intact microphthalmic strain more effectively than AGTH or a combination of AGTH and LtH. 


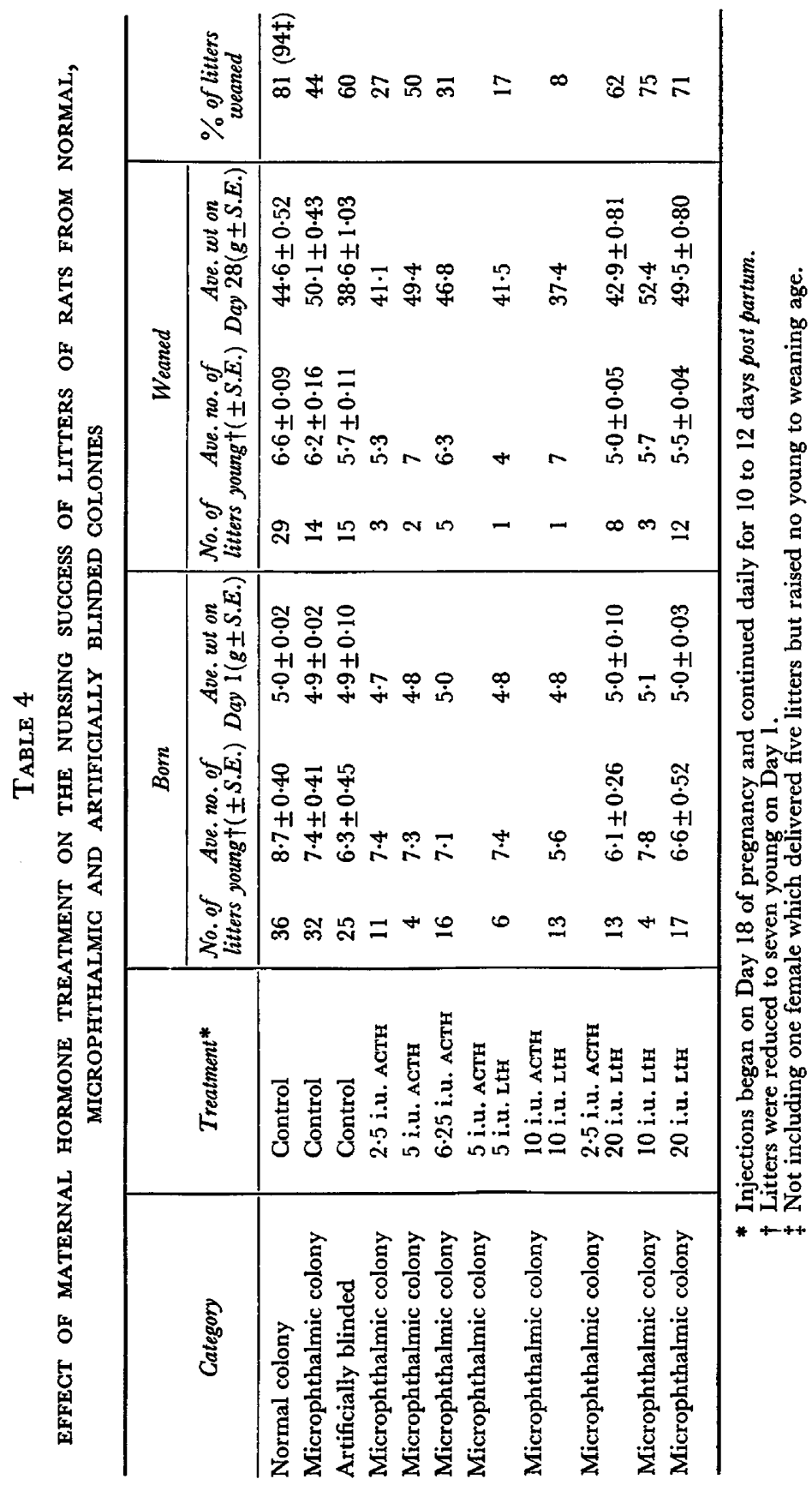


Supplementary therapy to the severely microphthalmic females with $\mathrm{LtH}$ alone alleviated the poor reproductive performance to a marked extent and the level of reproductive performance approached that of the females in the normal colony. The number of young weaned improved from a maximum of $44 \%$ with no hormone supplement to a level of 70 to $75 \%$ with doses of up to 20 i.u. of prolactin.

\section{DISGUSSION}

Microphthalmic female rats in the present study responded to relatively low levels of prolactin compared to the results reported by Meites, Nicoll \& Talwalker (1963), who stated that prolactin in doses of 30 or 60 i.u. daily did not induce mammary gland secretion in oestrogen-primed rats. They further stated that initiation of mammary secretion in the rat could usually be assumed to involve the release of АCTH as well as prolactin. However, in the microphthalmic strain used here, injections of AGTH in conjunction with LtH did not enhance lactation (see Table 4). Meites et al. (1963) also reported that 30 i.u. of prolactin and 2 i.u. of ACTH given together initiated mammary gland secretion in the rat. In the present study, 20 i.u. of $\mathbf{L t H}$ alone was adequate to initiate lactation in the parturient microphthalmic females.

The statement of Meites et al. (1963) that "Prolactin is essential for the initiation of lactation at about the time of parturition and for the maintenance of post partum lactation" was borne out in the present strain of microphthalmic rats. Prolactin injected 3 to 4 days before parturition and injected from 10 to 12 days post partum definitely improved their nursing performance.

Environmental stimuli also play a part in the lack of adequate milk secretion. Grosvenor \& Mena (1967) stated that "certain olfactory, visual and auditory stimuli reduce the amount of milk obtained by pups". However, all rats employed in the experimental work reported above, were housed in relatively quiet, isolated quarters with a minimum of disturbance.

Grosvenor, Mena, Dhariwal \& McCann (1967) stated that injection of rat stalk median eminence or prolactin inhibitor factor (PIF) before the young were suckled significantly reduced the amount of milk yield. It has also been repeatedly demonstrated that the PIF in the hypothalamus inhibits LtH release from the anterior pituitary (McGann, \& Friedman, 1960; Haun \& Sawyer, 1961; Schally, Kuroshima, Ishida, Redding \& Bowers, 1965; Gala \& Reece, 1965). Suckling depletes the PIF in the hypothalamus and removes the inhibition on the LtH release (Ratner \& Meites, 1964; Grosvenor, Mena \& Schaefgen, 1967; Minaguchi \& Meites, 1967; Convey \& Reece, 1969). With the release of increased amounts of $\mathbf{L t H}$, lactation ensues.

Two possible mechanisms are suggested to account for the poor lactation of intact microphthalmic females. Firstly, there may be a low level of LtH in the anterior pituitary with a relatively high level of PIF in the hypothalamus. This high level of PIF may inhibit LtH release, even in the presence of the early sucking stimulus which ordinarily removes the PIF. Secondly, there may be a low level of both LtH and PIF in the microphthalmic female and the sucking stimulus alone may be inadequate to reduce the PIF to the point where sufficient $\mathbf{L t H}$ is released to stimulate lactation. 
With the additional supplement of an outside source of $L$ th before and after parturition, the sucking stimulus may act in a synergistic manner to inhibit PIF and to permit an increase in the normal LtH production resulting in lactation. As sucking gradually increases in vigour, the PIF level will be further reduced and this, together with an exogenous supplement of $\mathrm{xtu}$ during the 1st week or 10 days after parturition, will allow the gradual release of adequate LtH to occur and a normal lactation cycle will supervene.

\section{ACKNOWLEDGMENTS}

This work was supported by USPHS, National Institute of Health, Grant 1R01NB06676-02. Acknowledgment is also made to the National Institute of Health for Prolactin NIH P-B-2-Bovine.

\section{REFERENCES}

Browman, L. G. (1967) Reproductive performance in the microphthalmic rat. Proc. Soc. exp. Biol. Med. 124, 1097.

CHAse, E. B. (1941) Studies on an anophthalmic strain of mice. II. Effect of congenital eyelessness on reproductive phenomena. Anat. Rec. 80, 33.

Convey, E. M. \& REECE, R. P. (1969) Restoration of pituitary lactogen released in response to suckling. Proc. Soc. exp. Biol. Med. 131, 543.

Eaton, O. N. (1937) A hereditary eye defect in guinea pigs. F. Hered. 28, 353.

GALA, R. R. \& REECE, R. P. (1965) Influence of neurohumors on anterior pituitary lactogen production in vitro. Proc. Soc. exp. Biol. Med. 120, 220.

Grosvenor, C. E. \& MENA, F. (1967) Effect of auditory, olfactory and optic stimuli upon milk ejection and suckling-induced release of prolactin in lactating rats. Endocrinology, 80, 840.

Grosvenor, C. E., Mena F., Dhariwal, A. P. S. \& MaGann, S. M. (1967) Reduction of milk secretion by prolactin-inhibiting factor; further evidence that exteroceptive stimuli can release pituitary prolactin in rats. Endocrinology, 81, 1021.

Grosvenor, G. E., Mena, F. \& Schaefgen, D. A. (1967) Effects of non-suckling interval and duration of suckling on the suckling-induced fall in pituitary prolactin concentration in the rat. Endocrinology, 81, 449.

HAIN, A. M. (1936) Microphthalmia and other eye defects throughout fourteen generations of albino rats. Proc. R. Soc. Edinb. 57, 64.

HAUN, C. K. \& SAwYER, C. H. (1961) The role of the hypothalamus in initiation of milk secretion. Acta endocr., Copenh. 28, 99.

KING, H. D. (1931) Studies on the inheritance of structural anomalies in the rat. Am. F. Anat. 48, 231.

MCGann, S. M. \& Friedman, H. M. (1960) The effect of hypothalamic lesions on secretion of luteotrophin. Endocrinology, 67, 597.

Mertes, J., Nicoll, G. S. \& TAlwalker, P. K. (1963) The central nervous system and the secretion and release of prolactin. In: Advances in Neuroendocrinology, pp. 238-277. Ed. A. V. Nalbandov. University of Illinois Press.

Minaguchi, H. \& Merres, J. (1967) Effects of suckling on hypothalamic LH-releasing factor and prolactin inhibiting factor, and on pituitary LH and prolactin. Endocrinology, 80, 603.

Ratner, A. \& Mertes, J. (1964) Depletion of prolactin-inhibiting activity of rat hypothalamus by estradiol or suckling stimulus. Endocrinology, 75, 377.

Schalty, A. V., Kuroshima, A., Ishida, Y., RedDing, T. W. \& Bowers, C. Y. (1965) The presence of prolactin inhibiting factor (PIF) in extracts of beef, sheep and pig hypothalami. Proc. Soc. exp. Biol. Med. 118, 350.

Yudkin, A. M. (1927) Congenital anophthalmia in a family of albino rats. Am. J. Ophthal. 10, 341. 